\title{
Epidemiologic profile of otorhinolaryngological, head and neck disorders in a tertiary hospital unit in Greece: a challenge for general practitioners?
}

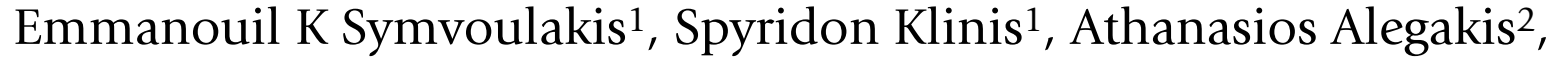 \\ Dionysios E Kyrmizakis ${ }^{3}$, Emmanouil I Drivas*3, Georgios Rachiotis4, \\ Anastas Philalithis ${ }^{1}$ and George A Velegrakis ${ }^{3}$
}

\begin{abstract}
Address: ${ }^{1}$ Department of Social Medicine, Faculty of Medicine, University of Crete, Greece, ${ }^{2}$ Biostatistics Laboratory, Faculty of Medicine, University of Crete, Greece, ${ }^{3}$ Department of Otorhinolaryngology, University of Crete, School of Medicine, Greece and ${ }^{4}$ Department of Epidemiology and Biostatistics, National School Public Health, Athens, Greece

Email: Emmanouil K Symvoulakis - symvouman@yahoo.com; Spyridon Klinis - spklinis@yahoo.gr;

Athanasios Alegakis - thalegak@med.uoc.gr; Dionysios E Kyrmizakis - dkyrmiz@yahoo.com; Emmanouil I Drivas* - em_drivas@yahoo.gr;

Georgios Rachiotis - gsrachmed@yahoo.com; Anastas Philalithis - tassos@med.uoc.gr; George A Velegrakis - gvel@med.uoc.gr

* Corresponding author
\end{abstract}

Published: 07 June 2006

BMC Ear, Nose and Throat Disorders 2006, 6:12 doi:10.1186/1472-68/5-6-12

This article is available from: http://www.biomedcentral.com/I472-68/5/6/12

(c) 2006 Symvoulakis et al; licensee BioMed Central Ltd.

This is an Open Access article distributed under the terms of the Creative Commons Attribution License (http://creativecommons.org/licenses/by/2.0), which permits unrestricted use, distribution, and reproduction in any medium, provided the original work is properly cited.
Received: 15 March 2006

Accepted: 07 June 2006

\begin{abstract}
Background: In Greece, primary care is still developing. The aim of this study was to define the epidemiologic profile of common otorhinolaryngological, head and neck disorders in order to help general practitioners to deal with them in a primary care future.
\end{abstract}

Methods: A total of 677I patients attended the Otorhinolaryngology emergency department of the University General Hospital of Heraklion (Crete), between January and December 2004. All cases were included in this retrospective study. The registry of the Otorhinolaryngology emergency department was analysed and age, sex, seasonality and clinical diagnosis were tabulated. All patients were evaluated by Otorhinolaryngologists. The classification of the cases was based on the main symptom or clinical sign that conditioned the reason for seeking care. Diagnoses were also coded according to the International Classification of Diseases (ICD-I0).

Results: The male to female ratio was I:I. The mean age for females was 36.3 years standard deviation (SD): $2 \mathrm{I}$.I and for males was 36.8 years $(S D=22.0)$. Eight hundred eighty six patients (13.1\%) formed the paediatric sub-group. Over $60 \%$ of the cases were classified in ten major groups of diagnosis. Acute tonsillitis (12.3\%) and acute pharyngitis $(9.0 \%)$ were the most common causes of all medical visits, followed by otitis media (7.6\%) and external ear canal obstruction by ear wax (6.2\%). Oedema of the larynx was detected in $0.4 \%$. A negative diagnosis of otorhinolaryngological, head and neck disorder was formulated in 553 patients (8.2\%). Hospitalization rate was $5.2 \%$. The highest rate of visits was registered in March.

Conclusion: Most patients used the facility as a primary care service. Real emergencies were a minority. Recovering data about which areas of Otorhinolaryngology deserve more emphasis might help primary health care providers to diagnose and manage the common otorhinolaryngological, head and neck disorders properly. 


\section{Background}

Issues of cost have influenced, dramatically, health care delivery in Western countries. General practitioners were encouraged to see and treat a wider spectrum of conditions in order to decrease costs [1].

In Greece, primary care is not fully developed, especially in urban areas. There is a lack of primary care settings and of general practitioners in the cities. People with a variety of disorders attend hospitals or private specialists in order to be reassured, diagnosed and treated [2]. The burden of hospital care is dramatically high and the financial impact is considerable. Additionally, every visit is an isolated episode of health care provision. The lack of care continuity, probably, could trigger further use of care services.

Otorhinolaryngological, head and neck disorders are common causes for seeking care in the emergency department of the University Hospital of Heraklion, Crete. Crete is the biggest island in Greece and the second biggest (after Cyprus) of the East Mediterranean. According to the 2001 census the population of Crete reaches 603.000 inhabitants [3]. The prefecture of Heraklion is the largest of the island, with approximately 295.000 people. There are two public hospital units in the city of Heraklion of which one is the University General Hospital and the other is a secondary level hospital unit. The two hospitals are alternatively on duty every 24 hours, being the duty days for the University hospital approximately 183 per year.

The aim of this study was to define the epidemiologic profile of the common otorhinolaryngological, head and neck conditions in order to help primary care providers to focus on them. In areas where general practice is under development, the medical records from specialised centres could represent the main source of information [4] regarding epidemiologic data. This does not reflect the real community needs but has to be considered when assessing, preliminarily, the health needs of a population.

\section{Methods}

All patients who attended the Otorhinolaryngology emergency department of the University General Hospital of Heraklion, Crete (Greece), between January to December 2004, were included in this retrospective study. From the registry of the Otorhinolaryngology emergency department, data related to the medical history, clinical examination and, whenever necessary, basic laboratory investigations were collected. Otorhinolaryngologists evaluated all patients. Sex, age, seasonality of the visits, most common otorhinolaryngological, head and neck disorders and their frequency were recorded. The clinical diagnosis, used for the classification of the cases, was based on the main symptom or clinical sign that condi- tioned the reason for seeking care. Diagnoses were also coded according to the International Classification of Diseases (ICD-10) [5]. We did not use the mentioned coding system for groups such as possible precancerous lesions and possible malignant neoplasms.

The total hospitalization rate (\%) was extracted. Specific Hospitalization Index was calculated, for the most common otorhinolaryngological, head and neck disorders related to hospitalisation, by dividing the number of the admitted patients in clinic by the number of patients seen at the emergency department, having a specific diagnosis of otorhinolaryngological, head and neck disorder.

Statistical analysis of the data was performed with the package SPSS 13.0. Categorical variables such as sex, seasonality of visits, type of disorder and hospitalisation of the cases were described as counts (n) or proportions (\%) while mean, standard deviation (SD) and median values were used for age (continuous variable). Graphical and tabular descriptions were also used to summarise data and present descriptive associations between different variables.

The present study conforms to the principles outlined in the Declaration of Helsinki. In our hospital, no ethical approval was necessary for this kind of retrospective study.

\section{Results}

A total of six thousand seven hundred seventy one patients (6771) attended the Otorhinolaryngology emergency department. Three thousand four hundred fifty four (51.0\%) patients were women and 3317 (49.0\%) were men. The mean age for females was 36.3 years (SD: 21.1) and for males was 36.8 years $(S D=22.0)$. Eight hundred eighty six patients $(13.1 \%)$ formed the paediatric subgroup. Age distribution of cases is shown in Figure 1. Monthly distribution of cases shows the highest rate of visits ( 736 or $10.9 \%$ ) during March, probably due to the increased number of cases with viral infections and allergic symptoms [Figure 2]. The pattern of otorhinolaryngological, head and neck disorders is shown in Table 1 . The median age of patients with the ten most common otorhinolaryngological, head and neck disorders is shown in Table 2. From the top ten groups of disorders only dizziness, epistaxis and benign paroxysmal positional vertigo were related to older age groups (patients with median age between 57 and 58 years). The other seven of the ten most common groups were related to younger age groups (patients with median age between 18 and 34 years), [Table 2].

Acute tonsillitis was observed in $12.3 \%$ (830 patients), followed by acute pharyngitis (9.0\%, 612 patients) and 


\section{Age distribution of cases}

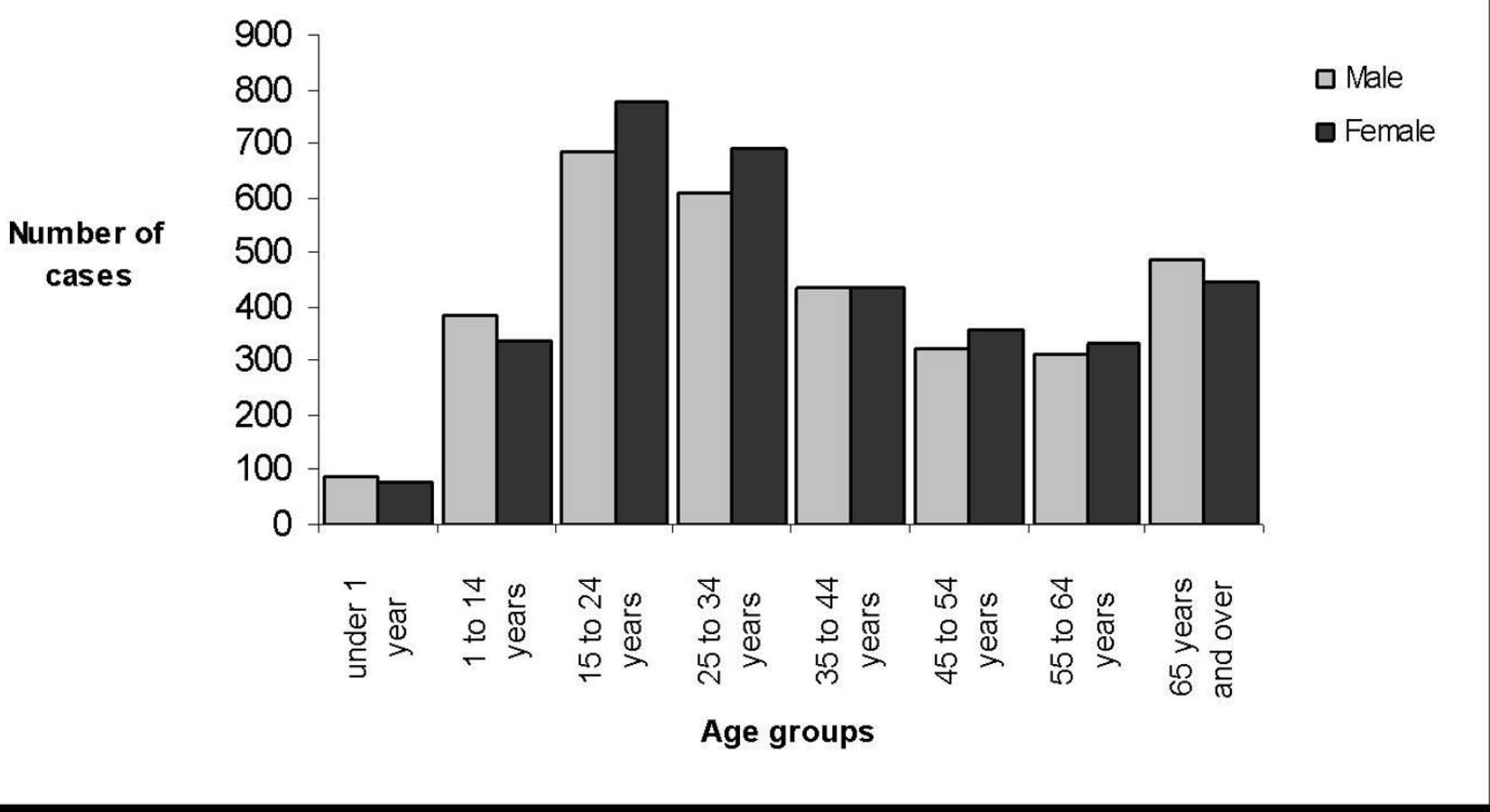

Figure I

Age distribution of all cases attended the Otorhinolaryngology emergency department.

acute otitis media (7.6\%, 516 patients). External ear canal obstruction by ear wax accounted for $6.2 \%$ (421 patients). Diffused or localized external otitis was observed in $6.0 \%$ (403 patients). Acute sinusitis was detected in a percentage of $5.5 \%$ (371 patients), followed by dizziness of various aetiology $(3.5 \%, 236$ patients) with exclusion of benign paroxysmal positional vertigo, which has been classified as a group apart. Foreign bodies of throat, nose and ear were observed in 3.5\% (236 patients) and nasal epistaxis in $3.4 \%$ (229 patients). In two hundred twenty two patients (3.3\%), Dix-Hallpike manoeuvre was favourable for a diagnosis of benign paroxysmal positional vertigo. The top ten groups of otorhinolaryngological, head and neck disorders accounted for over $60 \%$ of all cases while twenty four of low frequency groups of disorders accounted for less of 32\% [Table 1]. Of the low frequency groups, possible precancerous lesions were observed in a percentage of $0.6 \%$ (39 cases) and possible malignant neoplasms in $0.4 \%$ (30 cases).

Oedema of the larynx, per definition a life threatening condition was observed in 29 patients $(0.4 \%)$. In the group others $(3.7 \%)$ were included all disorder types with a lower frequency than $0.4 \%$, for each subtype (data not shown). No otorhinolaryngological, head and neck disorder was observed in 8.2\% (553 patients).

In $10 \%$ of the cases, consultations were performed within other specialities in the emergency department. For instance, consultations were performed within internal medicine specialists in $4.02 \%$ of the cases, paediatricians in $2.07 \%$, neurologists in $1.28 \%$, chest physicians in $0.68 \%$ and surgeons in $0.45 \%$. Consultations, within dentists, accounted for $0.32 \%$ of the cases and for the rest of the cases $(1.18 \%)$ within other specialities.

Hospitalisation rate was accounted for 5.2\% (352 patients). The ten most common otorhinolaryngological, head and neck disorders related to hospitalisation with the respective specific hospitalisation index are shown and described in Table 3.

\section{Discussion}

Otorhinolaryngological, head and neck disorders are among the common reasons of visit in the University General Hospital of Heraklion, the only one tertiary hospital unit in the island of Crete. Adolescents and young adults seem to be the patients who seek care more com- 


\section{Monthly distribution of medical visits}

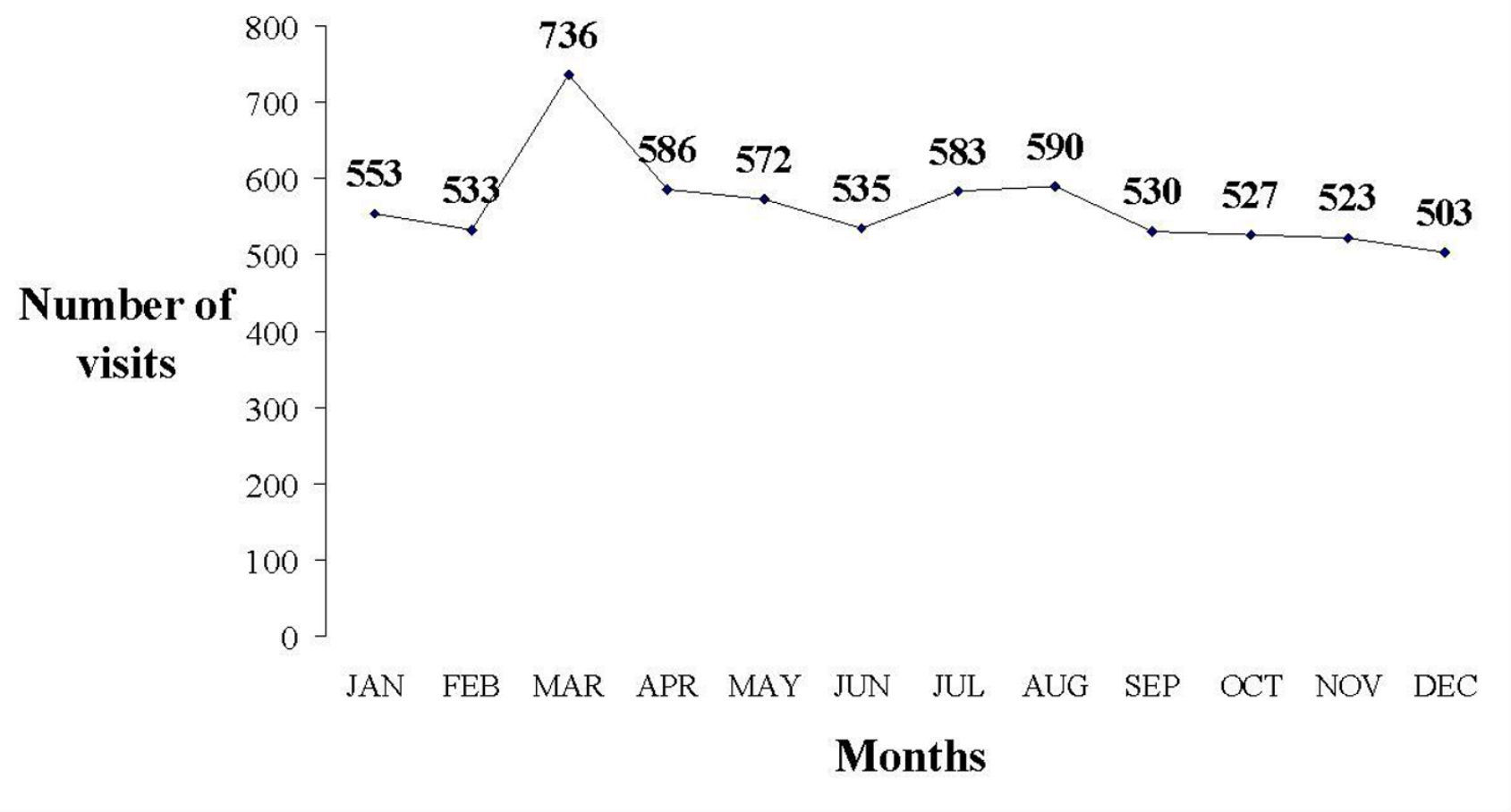

Figure 2

Monthly distribution of all visits in the Otorhinolaryngology emergency department.

monly. Females were slightly more than males. The most common disorder observed was acute tonsillitis. The top ten conditions accounted for over $60 \%$ of all cases. Five out of those ten groups are infectious diseases. Perez Obon et al. reported infectious disorders first, among the most frequent conditions, accounting for 41\% [6]. Our data suggest that infectious disorders are the leading reason for consultation. One out of two patients used the emergency department service having an infectious disorder.

Dizziness of various aetiology and benign paroxysmal positional vertigo were observed in similar frequencies (3.5\% and 3.3\%, respectively). It is shown that benign paroxysmal positional vertigo was the cause of seeking care in one out of two patients who presented with a 'dizziness' condition in the emergency department. Nose, ear, and the other injuries accounted for over 5.0\%. Various etiologic agents and different types of injuries (skin, soft tissue, vessel or bone lesions) result in different approaches of management. For this reason we reported a breakdown of injury subtypes according to the anatomical position of the noxious impact. Additionally, we cannot estimate, precisely, the total amount of otorhinolaryngo- logical, head and neck injuries; some patients with serious head, chest or abdominal life-threatening traumas and an otorhinolaryngological, head and neck co-injury were evaluated in different speciality settings within the emergency department.

Possible precancerous lesions and possible malignant neoplasms were, initially, diagnosed in a percentage of $0.6 \%$ and $0.4 \%$ respectively. These observations cannot be confirmed without cytological or histological findings. On the other hand most of the patients with possible precancerous disorders or cancer are seen in the regular Otorhinolaryngology outpatient settings since the onset of their complaints is gradual. A possible overlap with the group of indolent lymph node enlargement represents another point of scepticism.

Oedema of the larynx, per definition, a life threatening condition occurs in $0.4 \%$. Some other conditions as the diagnosis of foreign bodies, nasal epistaxis, injuries, various hypersensitivity reactions or their possible complications, need an urgent or a highly specialized initial medical approach. All these conditions accounted for $13.8 \%$. Timsit et al reported in a similar study that only 
Table I: Distribution of cases by type of disorder.

\begin{tabular}{|c|c|c|c|}
\hline $\begin{array}{l}\text { Type of } \\
\text { otorhinolaryngological head } \\
\text { and neck disorder }\end{array}$ & ICD- 10 & Cases (n) & Percentage (\%) \\
\hline Acute tonsillitis & j03 & 830 & 12.3 \\
\hline Acute pharyngitis & j02 & 612 & 9.0 \\
\hline Acute otitis media & $\mathrm{H} 66.9$ & 516 & 7.6 \\
\hline $\begin{array}{l}\text { External ear canal obstruction by } \\
\text { ear wax }\end{array}$ & $\mathrm{H} 6 \mathrm{I} .2$ & 421 & 6.2 \\
\hline Diffused or localized external otitis & $\mathrm{H} 60$ & 403 & 6.0 \\
\hline Acute sinusitis & J0I & 371 & 5.5 \\
\hline Dizziness* & R42 & 236 & 3.5 \\
\hline Foreign bodies & TI7.9, TI6 & 236 & 3.5 \\
\hline Nasal epistaxis & R04.0 & 229 & 3.4 \\
\hline $\begin{array}{l}\text { Benign paroxysmal positional } \\
\text { vertigo }\end{array}$ & H8I.I & 222 & 3.3 \\
\hline Otomycosis & $\mathrm{H} 62.2$ & 165 & 2.4 \\
\hline Seasonal allergic rhinitis & $\mathrm{J} 30.1, \mathrm{~J} 30.2$ & 158 & 2.3 \\
\hline Nose injuries & S00.3, SOI.2 & 156 & 2.3 \\
\hline Secretory otitis media & H65.9 & $15 \mid$ & 2.2 \\
\hline Various face, and neck injuries** & S00.9 & 137 & 2.0 \\
\hline Tinnitus and hearing loss & H93.I, H9I.9 & 124 & 1.8 \\
\hline Laryngitis & J04.0, J06 & 120 & 1.8 \\
\hline Stomatitis & $\mathrm{K} / 2$ & 84 & 1.2 \\
\hline Purulent rhinitis & J31.0 & 83 & 1.2 \\
\hline Ear injuries & S00.4, SOI.3 & 72 & 1.1 \\
\hline Chronic otitis media & $\mathrm{H} 66.3$ & 71 & 1.0 \\
\hline Facial nerve paralysis & G5I & 64 & 0.9 \\
\hline Lymphadenitis & L04.0 & 63 & 0.9 \\
\hline Seborrhoic cyst/furuncle & L02 & 61 & 0.8 \\
\hline $\begin{array}{l}\text { Temporo-mandibular joint } \\
\text { syndrome }\end{array}$ & K07.6 & 54 & 0.8 \\
\hline $\begin{array}{l}\text { Various acute hypersensitivity } \\
\text { reactions*** }\end{array}$ & J39.3 & 49 & 0.7 \\
\hline Peritonsillar abscess/phlegmon & $\mathrm{J} 36$ & 46 & 0.7 \\
\hline Indolent lymph node enlargement & C77.0 & 39 & 0.6 \\
\hline Possible precancerous lesions & & 39 & 0.6 \\
\hline Inflammation of salivary glands & $\mathrm{KII}$ & 38 & 0.6 \\
\hline Infectious Mononucleosis & B27 & 35 & 0.5 \\
\hline Possible malignant neoplasms & & 30 & 0.4 \\
\hline Oedema of the larynx & $\mathrm{J} 38.4$ & 29 & 0.4 \\
\hline Sudden hearing loss & $\mathrm{H} 9 \mathrm{I} .2$ & 24 & 0.4 \\
\hline Others & & 250 & 3.7 \\
\hline $\begin{array}{l}\text { No clinical findings of } \\
\text { otorhinolarynological, head and } \\
\text { neck disorders }\end{array}$ & & 553 & 8.2 \\
\hline Total & & 6771 & 100 \\
\hline
\end{tabular}

* All subtypes except benign paroxysmal positional vertigo

** Except those of nose and ear

*** Except oedema of the larynx

$10 \%$ of the consultations appeared to be real emergencies [7]. It seems that there was a primary care use of the Otorhinolaryngology emergency department facilities, as it has been proposed in other studies as well [8]. Our results suggest that general practitioners could provide a first appropriate contact care for patients with common otorhinolaryngological, head and neck disorders.
Otorhinolaryngological, head and neck diagnosis was negative in a percentage of $8.2 \%$. This fact, perhaps, could be explained by a variety of reasons. Transient and atypical minimal symptoms or somatoform stress reactions could increase consultation rates. Schmidt et al found that the incidence of hypochondriasis was relatively high (13\%) among the new patients who attended the Otorhi- 
Table 2: The ten most commonotorhinolaryngological, head and neck disorders and median age of the patients

Top ten groups of otorhinolaryngological, head and neck disorders
Median Age (years)
I. Acute tonsillitis

2. Acute pharyngitis

3. Diffused or localised external otitis

4. Acute otitis media

5. External ear canal obstruction by ear wax

6. Acute sinusitis

7. Dizziness*

8. Foreign bodies

9. Nasal epistaxis

10. Benign paroxysmal positional vertigo

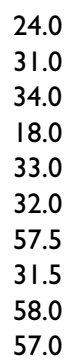

nolaryngology outpatient settings, with frequent overuse of care services and high consumption of drugs [9]. Furthermore the use of a specialized care service per definition cannot provide holistic approaches. Self-referred patients could misuse care services by attending different specialists in order to be sufficiently reassured. This fact maybe explains, partly, the paradox of the patients-non 'otorhinolaryngological, head and neck' patients who attended the Otorhinolaryngology emergency department. Research needs to be done in order to define why more than five hundred fifty persons, in one-year period, asked for care without findings of otorhinolaryngological, head and neck disorders.

The hospitalisation rate was $5.2 \%$. The specific hospitalisation index, as shown in the Table 3 , is a pure value and provides information regarding the inpatient or outpatient management of a certain otorhinolaryngological, head and neck disorder. Among the ten most common otorhinolaryngological, head and neck disorders related to hospitalisation, accounting for $78 \%$ of the 352 cases, oedema of the larynx, sudden hearing loss, peritonsillar abscess/phlegmon and facial nerve paralysis show the highest specific hospitalisation index. This type of information could be used, as a tool in order to discriminate which conditions should be managed at a secondary care environment.

The limitation of our study consists in the fact that our data are drawn from only one hospital institution. It is difficult to assess the real needs of the community if there is a lack of evidence from primary care settings or without

Table 3: The ten most commonotorhinolaryngological, head and neck disorders related to hospitalisation and specific hospitalisation index (SHI).

\begin{tabular}{|c|c|c|c|}
\hline $\begin{array}{l}\text { Top ten } \\
\text { otorhinolaryngological, head } \\
\text { and neck disorders related to } \\
\text { hospitalisation }\end{array}$ & $\begin{array}{l}\text { Emergency department visits } \\
n\end{array}$ & Admissions $n$ & S.H.I** (range: $0-I$ ) \\
\hline Dizziness (all types)* & 458 & 53 & 0.12 \\
\hline Facial nerve paralysis & 64 & 47 & 0.73 \\
\hline Peritonsillar abscess/phlegmon & 46 & 44 & 0.96 \\
\hline Acute tonsillitis & 830 & 31 & 0.03 \\
\hline Oedema of the larynx & 29 & 29 & 1.00 \\
\hline Sudden hearing loss & 24 & 23 & 0.96 \\
\hline Acute sinusitis & 371 & 16 & 0.04 \\
\hline Nasal epistaxis & 229 & 12 & 0.05 \\
\hline Various hypersensitivity reactions & 49 & 12 & 0.24 \\
\hline Indolent lymph node enlargement & 39 & 8 & 0.21 \\
\hline
\end{tabular}

\footnotetext{
* including benign paroxysmal positional vertigo

** SHI = Number of admitted patients in clinic/Number of patients seen at emergency department, having a specific diagnosis of otorhinolaryngological, head and neck disorder (in one year).

$\mathrm{SHI}=0$, none of the patients who attended the emergency department with a specific otorhinolaryngological, head and neck disorder was hospitalised (in one year).

$\mathrm{SHI}=\mathrm{I}$, all the patients who attended the emergency department with a specific otorhinolaryngological, head and neck disorder were hospitalised (in one year).
} 
large community-based surveys $[10,11]$. On the other hand these data largely support the hypothesis that there is use of the hospital services as a primary care facility [12]. By using this information as baseline we could have a preliminary approach regarding the health needs of this population.

\section{Conclusion}

General practitioners should have the skills to deal with the most common disorders. Many of the otorhinolaryngological, head and neck conditions could be managed at the level of primary health care [13]. Retrieving data and incorporating them into the educational and training program of general practitioners might help to achieve successful management of the frequent otorhinolaryngological, head and neck problems in a primary care future. This may decrease the burden of hospital care and improve the quality of care provision in terms of proper referrals, holistic view of patient's condition and continuity of care.

\section{Competing interests}

The author(s) declare that they have no competing interests.

\section{Authors' contributions}

EKS, SK, AP, GAV were involved with the study conception. EKS, SK, DK prepared the manuscript. EKS, SK, AA, GR and EID performed the data acquisition and interpretation. DK, AP and GAV were involved in revising the article for important intellectual content and technical details. All authors read and approved the final manuscript.

\section{Acknowledgements}

We would like to thank Dr Antoniou Katerina for her help in editing and technical details related to the revision of the manuscript. The study was not supported from a founding body or any other source. The department of Otorhinolaryngology and the department of Social Medicine contributed all the materials essential for the study.

\section{References}

I. Federman DG, Concato J, Kirsner RS: Comparison of Dermatologic diagnoses by Primary Care Practitioners and Dermatologists. A review of the literature. Arch Fam Med 1999, 8:170-2.

2. Symvoulakis EK, Krasagakis K, Komninos ID, Kastrinakis I, Lyronis I, Philalithis A, Tosca AD: Primary care and pattern of skin diseases in a mediterranean island. BMC Family Practice 2006, 7:6.

3. Census 200I: General secretarial of national statistical service of Greece. (Online). 200 I [http://www.statistics.gr]. (Accessed I5 February 2006)

4. Baghestani S, Zare S, Mahoobi AA: Skin disease patterns in Hormozgan, Iran. Int I Dermatol 2005, 44:64I-5.

5. W.H.O: International Statistical Classification of Diseases and related Health Problems. I0th Revision, version for $2003 . \quad[$ http://www3.who.int/icd/vollhtm2003/fr-icd.htm]. (Accessed 28 April 2006)

6. Perez Obon J, Rivares Esteban J, Leache Pueyo J, Fernandez Liesa R, Marin Garcia J, Sevil Navarro J, Mateo Blanco A: An outpatient study in ENT (otorhinolaryngology) emergencies at a general hospital. Acta Otorrinolaringol Esp 1995, 46:298-304.

7. Timsit CA, Bouchene K, Olfatpour B, Herman P, Tran Ba Huy P: Epidemiology and clinical findings in 20,563 patients attending the Lariboisiere Hospital ENT Adult Emergency Clinic. Ann Otolaryngol Chir Cervicofac 200I, I I 8:2 I5-24.

8. Pino Rivero V, Rejas Ugena E, Keituqwa Yanez T, Alcaraz Fuentes M, Marcos Garcia M, Trinidad Ruiz G, Blasco Huelva A: Descriptive study of 21,804 ENT emergencies in a third level hospital. An Otorrinolaringol Ibero Am 2003, 30:237-45.

9. Schmidt AJ, van Roosmalen R, van der Beek JM, Lousberg R: Hypochondriasis in ENT practice. Clin Otolaryngol Allied Sci 1993. 18:508-II.

10. Hannaford PC, Simpson JA, Bisset AF, Davis A, McKerrow W, Mills $R$ : The prevalence of ear, nose and throat problems in the community: results from a national cross-sectional postal survey in Scotland. Fam Pract 2005, 22:227-33.

II. Amusa YB, ljadunola IK, Onayade OO: Epidemiology of otitis media in a local tropical African population. West Afr J Med 2005, 24:227-30.

12. Granick MS, Obeiter RD: Patient profile of an otolaryngologic emergency department. JAMA 1983, 250:933-5.

13. O'Driscoll K, Donnelly MJ, McShane DP, Burns H: An audit of the E.N.T. casualty service at the Royal Victoria Eye and Ear Hospital. Ir J Med Sci 1993, 162:462-5.

\section{Pre-publication history}

The pre-publication history for this paper can be accessed here:

http://www.biomedcentral.com/1472-6815/6/12/prepub

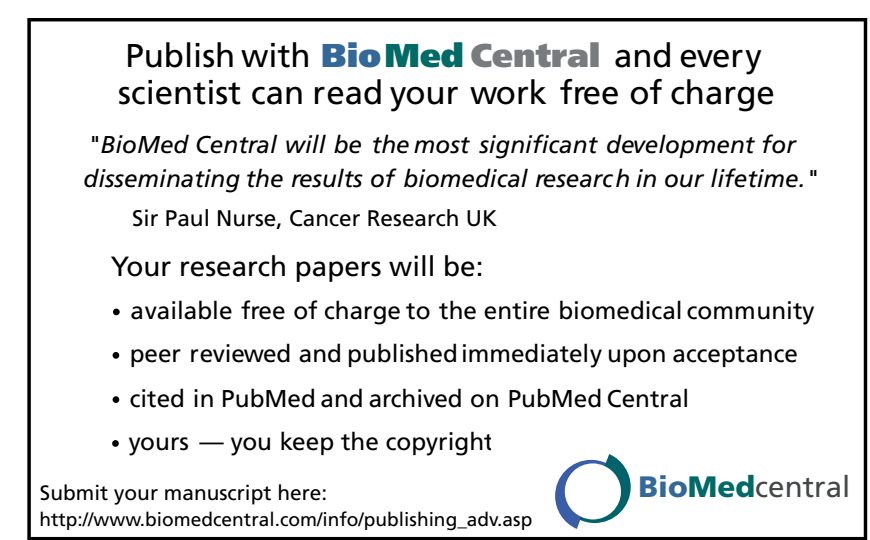

